\title{
Golimumab in radiographic and nonradiographic axial spondyloarthritis: a review of clinical trials
}

\author{
This article was published in the following Dove Press journal: \\ Drug Design, Development and Therapy \\ I July 2016 \\ Number of times this article has been viewed
}

\author{
Eric Toussirot ${ }^{1-5}$ \\ Charline Vauchy' \\ Delphine Binda' \\ Fabrice Michel $^{6}$ \\ 'Clinical Investigation Center in \\ Biotherapy, Intitut National de la \\ Santé et de la Recherche Médicale \\ CIC-I43I, 'Fédération Hospitalo- \\ Universitaire Integrated Center for \\ Research in inflammatory Diseases, \\ ${ }^{3}$ Department of Rheumatology, \\ University Hospital of Besançon, \\ Besançon, France; ${ }^{4}$ Department of \\ Therapeutics, ${ }^{5}$ Equipe d'accueil \\ EA 4266: "Pathogenic Agents \\ and Inflammation", University of \\ Franche-Comté, 'Department of \\ Neuromuscular Examinations and \\ Diseases, University Hospital of \\ Besançon, Besançon, France
}

\begin{abstract}
Axial spondyloarthritis ( $\mathrm{Ax} \mathrm{SpA}$ ) refers to chronic inflammatory rheumatic diseases that mainly affect the axial skeleton, leading to erosions and new bone formation in the sacroiliac joints and/or the spine. Ax SpA includes the radiographic form of the disease, ie, ankylosing spondylitis (AS), and the nonradiographic Ax SpA (non-Rx Ax SpA) forms. Anti-tumor necrosis factor alpha $(\mathrm{TNF} \alpha)$ agents are used in the treatment of Ax SpA in patients who do not respond to or are intolerant to nonsteroidal anti-inflammatory drugs. In these patients, anti-TNF $\alpha$ agents show promising results by targeting the inflammatory process and providing symptomatic relief. Golimumab is a fully human anti-TNF $\alpha$ agent that is currently approved for the treatment of both AS and non-Rx Ax SpA in Europe. This review focuses on the results of clinical trials with golimumab for the treatment of AS (GO-RAISE studies) and non-Rx Ax SpA (GO-AHEAD study) and on the effects of this agent on imaging findings (radiographic progression, magnetic resonance imaging inflammation) as well as on biological parameters. Overall, golimumab is a valid therapeutic option in patients with AS and non-Rx Ax SpA in Europe.
\end{abstract}

Keywords: anti-TNF $\alpha$, golimumab, axial spondyloarthritis

\section{Introduction}

Spondyloarthritis $(\mathrm{SpA})$ represents a group of disorders with common clinical and radiographic characteristics as well as genetic background. ${ }^{1}$ This group includes five individualized subtypes: ankylosing spondylitis (AS), which is the prototype of SpA, psoriatic arthritis (PsA), inflammatory bowel disease-associated arthritis, reactive arthritis, and undifferentiated $\mathrm{SpA}$. These diseases mainly affect the axial skeleton, leading to erosions and new bone formation in the sacroiliac joints (SIJ) and/or the spine. According to this clinical presentation, such disorders are currently called as axial $\mathrm{SpA}$ (Ax SpA). Other clinical features of $\mathrm{SpA}$ are asymmetrical oligoarthritis, enthesitis, dactylitis, and specific extraskeletal manifestations such as psoriasis, uveitis, and chronic inflammatory bowel disease. ${ }^{2}$

AS is usually diagnosed using conventional pelvic X-ray examination, which shows bilateral sacroiliitis. Radiographic sacroiliitis is included in the modified New York criteria and classification of AS (Grade II and higher bilaterally or Grade III and higher unilaterally is required for fulfilling the diagnosis). ${ }^{3}$ Nonradiographic (non-Rx) Ax SpA corresponds to a subset of patients without definite radiographic sacroiliitis and is considered to represent an earlier stage of AS. Recently, the Assessment of SpondyloArthritis international Society (ASAS) has developed a set of criteria for the detection of patients with early Ax SpA that includes evidence of sacroiliitis visible by magnetic resonance imaging (MRI), chronic back pain, HLA-B27 positivity, and other nonarticular symptoms. ${ }^{4}$ According to these criteria, patients may or may not 
have radiographic/MRI changes on imaging, corresponding to $\mathrm{Rx}$ and non-Rx forms of $\mathrm{Ax} \mathrm{SpA}$, respectively. Despite some differences between these two forms of the disease in terms of sex ratio or elevation of acute-phase reactants, it is considered that both subgroups do not differ substantially in disease activity and in terms of the consequences of the disease. ${ }^{5}$ Indeed, AS and Ax SpA, in general, are debilitating diseases that markedly affect patients' quality of life. Significant functional restrictions in AS patients with disease duration of more than 20 years have been reported, especially in patients who smoke and in those whose professions require strenuous physical activity. ${ }^{6}$ Finally, AS carries a large economic burden due to reduced productivity. ${ }^{7}$

Based on the European League Against Rheumatisms/ ASAS recommendations, the first-line therapy for AS and Ax SpA is nonsteroidal anti-inflammatory drugs (NSAIDs) ${ }^{8}$ Conventional synthetic disease-modifying antirheumatic drugs (especially methotrexate) are ineffective in Ax SpA, although specific products such as sulfasalazine may have beneficial effects in certain patients, especially those with peripheral involvement. For patients with active disease despite NSAIDs, or for those who are intolerant to NSAIDs, the only alternative treatments currently available are antitumor necrosis factor alpha (TNF $\alpha$ ) agents. ${ }^{9}$

This paper reviews data on the efficacy and safety of the use of golimumab, a human monoclonal antibody against TNF $\alpha$, for the treatment of Ax SpA with or without radiographic changes. Golimumab is the latest anti-TNF $\alpha$ agent to have been introduced on the market, and its use in clinical practice is progressively increasing.

\section{Methods}

We performed a Medline search via PubMed using the following terms "golimumab" AND "ankylosing spondylitis" OR "spondyloarthritis" OR "axial spondyloarthritis" and restricted our analysis to clinical trials. Only papers published in English language were analyzed. The Medline search covered the period from 2005 to 2016 .

\section{Currently available anti-TNF $\alpha$ agents}

Currently, five anti-TNF $\alpha$ agents, namely, infliximab, etanercept, adalimumab, certolizumab pegol, and golimumab are available for the treatment of active AS despite the already existing NSAID treatment. ${ }^{10}$ Four are licensed for the treatment of non-Rx Ax SpA in Europe: adalimumab, etanercept, certolizumab pegol, and golimumab. To date, none of these agents has been approved for the treatment of non-Rx Ax SpA in the USA.

\section{Introduction to golimumab}

Golimumab (SIMPONI ${ }^{\circledR}$; Janssen Biotech Inc, PA, USA; MSD, Hertfordshire, UK), CNTO-148, is a human IgG1 $\kappa$ antagonist monoclonal antibody with a molecular mass of $150 \mathrm{kDa}$. It is a fully human bivalent monoclonal antibody specific for TNF $\alpha$ that is able to bind both soluble and transmembrane forms of TNF $\alpha$. Golimumab is produced by a cell line of murine hybridomas with recombinant DNA technology. This agent has multiple sites of glycosylation. ${ }^{11}$ In clinical trials in patients with rheumatoid arthritis (RA), PsA, and SpA, the administration of golimumab was associated with a decrease in C-reactive protein (CRP), interleukin (IL)-6, vascular endothelial growth factor, and metalloproteinases. ${ }^{12}$ The mean time required in healthy subject to reach maximum serum concentration after subcutaneous golimumab injection ranges from 2 to 6 days. The mean half-life of the product is estimated to be between 11 and 19 days in subjects who received a dose of $3 \mathrm{mg} / \mathrm{kg}$ or higher. Patients with higher body weight tend to have lower trough serum golimumab concentration at steady state, explaining some clinical results (see "Clinical efficacy of golimumab in Ax SpA: the GO-RAISE and GO-AHEAD trials" section). ${ }^{13}$ In patients older than 65 years, no dose adjustment is required. There is no pharmacokinetic data for patients with renal or hepatic impairment. ${ }^{13}$ Golimumab is available as a sterile solution of $50 \mathrm{mg}(0.5 \mathrm{~mL})$ or $100 \mathrm{mg}(1 \mathrm{~mL})$ in a prefilled syringe or in a prefilled SmartJect ${ }^{\circledR}$ autoinjector (Janssen Biotech Inc., Horsham, PA, USA). The standard dosage in SpA, RA, and PsA is $50 \mathrm{mg}$ administered subcutaneously once a month. For patients with body weight $>100 \mathrm{~kg}$ who do not achieve a clinical response after three or four injections, the dose may be increased to $100 \mathrm{mg}$ once a month. ${ }^{14}$

\section{Clinical efficacy of golimumab in Ax SpA: the GO-RAISE and GO-AHEAD trials}

Golimumab has been evaluated in two pivotal randomized controlled studies ${ }^{15,16}$ assessing its safety and efficacy in patients with AS and in patients with non-Rx Ax SpA. Data on the long-term effects ( 2 and 5 years) of golimumab in AS are also available..$^{17,18}$

The clinical efficacy of golimumab in AS was evaluated in the GO-RAISE study. ${ }^{15}$ This was a randomized placebo-controlled trial evaluating the safety and efficacy of golimumab $50 \mathrm{mg}$, golimumab $100 \mathrm{mg}$, or placebo every 4 weeks in 356 patients with AS. The patients had active disease defined by a Bath Ankylosing Spondylitis Disease Activity (BASDAI) score $\geq 4$ and a back pain score $\geq 4$. Included patients did not respond adequately to first-line therapy with NSAIDs. The primary end point was the proportion of patients who were 
ASAS20 responders at Week 14. At Week 16, patients receiving placebo or golimumab $50 \mathrm{mg}$ who had $<20 \%$ improvement in total back pain and morning stiffness entered early escape to $50 \mathrm{mg}$ golimumab or $100 \mathrm{mg}$ golimumab, respectively. After 14 weeks, $59.4 \%, 60.0 \%$, and $21.8 \%$ of patients treated with golimumab $50 \mathrm{mg}$, golimumab $100 \mathrm{mg}$, and placebo were ASAS20 responders, respectively $(P<0.001$; Table 1). At the end of the study at Week 24, 43.5\%, 54.3\%, and $15.4 \%$ of patients, respectively, achieved an ASAS40 response. At Week 24, patients receiving golimumab also had a significant improvement in the other secondary end points, ie, BASDAI score, Bath Ankylosing Spondylitis Functional Index (BASFI), scores for physical and mental components of the Short Form (SF)-36 health survey, and the Jenkins Sleep Evaluation Questionnaire score, but not in Bath Ankylosing Spondylitis Metrology Index. In the golimumab groups, the clinical response was observed 4 weeks after the first injection. In addition, the benefit of golimumab treatment was consistent across subgroups of sex, race, age, and body weight $\leq 87 \mathrm{~kg}$ for golimumab $50 \mathrm{mg}$ and $\leq 75 \mathrm{~kg}$ for golimumab $100 \mathrm{mg}$. In the combined golimumab group, response rate at Week 14 was greater in patients with high CRP levels $(>0.6 \mathrm{mg} / \mathrm{dL})$ compared to those with low CRP levels $(\leq 0.6 \mathrm{mg} / \mathrm{dL})$.

Golimumab was evaluated in patients with non-Rx Ax SpA in the GO-AHEAD study. ${ }^{16}$ This study was a Phase III, double-blind, randomized placebo-controlled trial evaluating golimumab $50 \mathrm{mg}$ every 4 weeks versus placebo in 198 patients. Patients had active disease defined by BASDAI $\geq 4$ and a spinal pain score of $\geq 4$. All patients had non-Rx Ax SpA according to the ASAS criteria and were nonresponders to or intolerant to NSAIDs, as well as being naïve to anti-TNF $\alpha$ agents. A subgroup of patients with objective signs of inflammation (OSI) defined by evidence of sacroiliitis on MRI and/or CRP levels higher than the upper limit of normal was analyzed for primary and secondary end points and adverse events. The primary end point was the proportion of patients achieving an ASAS20

Table I Proportion of ASAS20 responders in the GO-RAISE and GO-AHEAD studies

\begin{tabular}{|c|c|c|c|}
\hline Study & Placebo & $\begin{array}{l}\text { Golimumab } \\
50 \mathrm{mg}\end{array}$ & $\begin{array}{l}\text { Golimumab } \\
60 \mathrm{mg}\end{array}$ \\
\hline $\begin{array}{l}\text { GO-RAISE, primary } \\
\text { end point at Week } 14^{15}\end{array}$ & 21.8 & 59.4 & 60 \\
\hline GO-RAISE, 2 years ${ }^{17}$ & 38.5 & 60.1 & 71.4 \\
\hline $\begin{array}{l}\text { GO-AHEAD, primary } \\
\text { end point at Week } 16^{16}\end{array}$ & 40 & 71.1 & NA \\
\hline
\end{tabular}

Abbreviations: ASAS, Assessment of SpondyloArthritis international Society; NA, not available. response at Week 16. ASAS20 response at this time point was observed in $71.1 \%$ versus $40 \%$ of patients treated with golimumab $50 \mathrm{mg}$ and placebo, respectively $(P<0.001$; Table 1). Analysis of secondary end points including ASAS40 response, BASDAI 50 (50\% improvement in the BASDAI), ASAS partial remission, and mean changes in Spondyloarthritis Research Consortium of Canada MRI SIJ score revealed significant improvement in patients treated with golimumab. Patients in the OSI subgroup demonstrated a higher ASAS20 response (76.9\%) than patients receiving placebo $(37.5 \%)(P<0.0001)$, whereas patients with negative MRI and normal CRP levels showed no difference in ASAS20 response ( $47.4 \%$ versus $50 \%, P=0.87$; Table 1$)$. In addition, patients with negative MRI and CRP levels above the upper limit of normal responded to treatment slightly better compared to the group with positive MRI.

Patients from the GO-RAISE study were followed up for 5 years. At Week 24, patients still receiving placebo crossed over to golimumab $50 \mathrm{mg}$. Although the placebo-controlled part of the study ended at Week 24, patients and investigators remained blinded through Week 24 as regards the golimumab dose (50 mg or $100 \mathrm{mg}$ golimumab). ${ }^{17}$ At Week $104,38.5 \%, 60.1 \%$, and $71.4 \%$ of patients initially receiving placebo, $50 \mathrm{mg}$, and $100 \mathrm{mg}$ golimumab, respectively, were ASAS20 responders and 38.5\%, 55.8\%, and 54.3\%, respectively, had ASAS40 response. Mean BASDAI and BASFI scores were $<3$ at Week 104 for all treatment regimens. From Week 104-252, the golimumab dose could be adjusted at the discretion of the investigator (up to $100 \mathrm{mg}$ for patients in the $50 \mathrm{mg}$ group or reduced to $50 \mathrm{mg}$ for patients in the $100 \mathrm{mg}$ group). ${ }^{18}$ The clinical improvement observed in patients receiving golimumab through Week 24 was maintained through Week 256: in an overall intent-to-treat analysis, response rates for ASAS20 and ASAS40 were $66 \%$ and $57 \%$, respectively. BASDAI 50\% improvement response was $55.9 \%$. Of the 356 patients initially enrolled in the study, the response rates among the 255 patients who continued golimumab treatment through Week 252 were consistent.

\section{The effects of golimumab on imaging: radiographic progression and $\mathrm{MRI}$ inflammation}

Radiographic damage in AS is evaluated using a validated scoring system, namely the modified Stoke Ankylosing Spondylitis Spine Score. ${ }^{19}$ There is an open debate about the effects of anti-TNF $\alpha$ agents on radiographic progression and their ability to slow down the process of ligamentous ossification. ${ }^{20}$ It is currently considered that this effect is not demonstrated for etanercept, adalimumab, and infliximab, 
since studies have shown no statistically significant difference in progression of structural damage at 2 years in AS patients receiving these agents as compared to placebo. ${ }^{21-23}$ However, some methodological aspects limit these findings. On the contrary, one observational cohort study showed that patients with AS who received anti-TNF $\alpha$ agents had a 50\% reduction in the odds for radiographic progression compared to those who did not receive these agents. ${ }^{24}$ Thus, examining the effect of golimumab on spinal radiographic progression is a relevant issue. This very question was investigated in the GO-RAISE study, with an analysis of two different doses of golimumab, 50 and $100 \mathrm{mg}$, on the rate of radiographic progression in patients with AS over 4 years. No difference in modified Stoke Ankylosing Spondylitis Spine Score was observed between golimumab 50 and $100 \mathrm{mg}$, and the radiographic rate was stable at 2 and 4 years, suggesting no progression of new bone formation over the course of the study. ${ }^{25}$ Conversely, these data indicated no retardation of spinal ossification. It was also observed that patients with baseline syndesmophytes and/or high baseline CRP levels $(>1.5 \mathrm{mg} / \mathrm{dL})$ progressed more than patients without syndesmophytes or with low CRP levels $(\leq 1.5 \mathrm{mg} / \mathrm{dL})$.

It has been reported that infliximab and other anti-TNF $\alpha$ agents may reduce spinal inflammation as detected by MRI. ${ }^{26}$ In a subgroup analysis of 98 patients from the GO-RAISE study, the effects of golimumab on MRI spinal inflammation were examined. ${ }^{27}$ These patients had spinal MRI at baseline and at Weeks 14 and 104 that were scored for inflammation (bone marrow edema) and erosions using the AS spine MRI activity index (ASspiMRI-a). ${ }^{28}$ At baseline, ASspiMRI-a scores were lower in the golimumab $100 \mathrm{mg}$ group versus the placebo and golimumab $50 \mathrm{mg}$ groups. At Week 14, there was an improvement in the MRI score that was of greater magnitude in the golimumab $50 \mathrm{mg}$ group compared to placebo $(P=0.047)$, whereas there was no significant difference between golimumab $100 \mathrm{mg}$ group and placebo. However, after post hoc analysis and adjustment for disparities in baseline characteristics, improvements in ASspiMRI-a were shown to be greater in golimumab 50 and $100 \mathrm{mg}$ groups versus placebo $(P=0.011$ and $P=0.0022$, respectively). In addition, ASspiMRI-a score improvements were maintained at Week 104 and correlated with improvement of disease activity (AS Disease activity - ASDAS score) and CRP levels, but not with other key clinical AS outcomes such as BASDAI, BASFI, back pain, and morning stiffness. Higher baseline CRP levels were associated with greater improvement in ASspiMRI-a score from baseline to Week 104. There are no available data on the effects of golimumab on radiographic progression and/or spinal MRI inflammation in patients with non-Rx Ax SpA.

\section{Effects of golimumab on biological markers}

Previous studies in patients with AS, RA, or PsA have reported the effects of golimumab on acute-phase reactants (CRP, IL-6). ${ }^{14,29}$ Inflammatory biomarkers were analyzed in the GO-RAISE and GO-AHEAD trials as predictors of response to treatment. ${ }^{15,16}$ In the GO-RAISE study, ASAS20 response in the combined golimumab group at Week 14 was higher in patients with high CRP levels compared to those with low CRP levels ( $>0.6$ and $\leq 0.6 \mathrm{mg} / \mathrm{dL}: 66.1 \%$ and $49.5 \%$; $>1.5$ and $\leq 1.5 \mathrm{mg} / \mathrm{dL}: 70.3 \%$ and $51.9 \%) .{ }^{15}$ Similar findings were observed in the GO-AHEAD study, which reported a better ASAS20 response in the OSI population (with positive SIJ MRI and/or elevated CRP) and in the subgroup of patients with elevated CRP at baseline (87.2\% versus $36.6 \%$ for patients with elevated CRP versus normal CRP). ${ }^{16}$ A subanalysis of the GO-RAISE study attempted to identify serum biomarkers associated with clinical improvement in patients with AS receiving golimumab. ${ }^{30}$ Serum samples were tested for selected markers using Luminex, enzyme-linked immunosorbent assay techniques, and HumanMAP protein profiling analysis. The selected serum markers included inflammatory cytokines, bone remodeling and cartilage markers, metalloproteinases, adipokines, angiogenesis markers, and adhesion molecules. In this analysis in 100 patients, significant decreases in several serum proteins at Weeks 4 and 14 were observed in patients under golimumab compared to those taking placebo. The results showed that patients who achieved an ASAS20 response at Week 14 had lower baseline levels of insulin, von Willebrand factor, apolipoprotein $\mathrm{C} 3$, and leptin compared to patients who did not. At Weeks 4 and 14, ASAS20 responders continued to have lower levels of these markers, as well as lower levels of complement C3, CRP, IL-6, and serum amyloid $\mathrm{P}$ compared to nonresponding patients. Interestingly, the combination of two or three markers (baseline levels of N-terminal propeptide of Type 1 collagen and insulin in one model; and leptin, immunoglobulin M, and vascular endothelial growth factor in a second model) was more strongly predictive of various clinical outcomes (ASAS20, BASDAI 50, and BASFI) than CRP alone.

\section{Effects of golimumab on quality of life}

Golimumab was shown to improve health-related quality of life in the GO-RAISE trial. ${ }^{15}$ The SF-36 mental component summary score improved from baseline to Week 14 in all 
golimumab groups compared with placebo, and these results were sustained through Week 24 in the golimumab100 mg and in the combined golimumab groups. At 2 years, patients who achieved ASDAS inactive disease or major improvement had a significantly greater improvement in SF-36 physical and component summary scores and productivity than patients who did not meet these end points. ${ }^{17}$ In the GOAHEAD study, similar findings were observed, with greater changes from baseline in the golimumab group compared to placebo for SF-36 physical and mental component scores, AS quality of life, and EuroQol 5 domain questionnaire. ${ }^{31}$

\section{Effects of golimumab on enthesitis}

Three scoring systems were used to assess entheseal involvement and changes in entheseal tenderness in patients from the initial 24-week GO-RAISE trial, namely the 12-point Berlin index, the 17-point University of California San Francisco index, and the 13-point Maastricht AS Enthesitis Score. ${ }^{32}$ Three hundred and fifty-five patients enrolled in the trial had enthesitis data available for analysis at Week 52. The 17-point University of California San Francisco index appeared to be more sensitive in detecting a significant improvement from baseline versus placebo in the golimumab $100 \mathrm{mg}$ group at Weeks 14 and 24. Patients with non-Rx Ax SpA participating in the GO-AHEAD study also had entheseal assessment using the 13-point Maastricht AS Enthesitis Score, and the results showed a significant improvement at Week 16 in the golimumab group. ${ }^{16}$

\section{Safety profile of golimumab in patients with Ax SpA}

Data from the GO-RAISE and GO-AHEAD studies, as well as from long-term extension studies, showed that golimumab was, in general, well tolerated, with a pattern of adverse events similar to that of other anti-TNF $\alpha$ agents. ${ }^{15-18}$ Through Week 24 in the GO-RAISE trial, 3.6\%, 6.4\%, and 5.4\% of the patients in the golimumab $50 \mathrm{mg}$, golimumab $100 \mathrm{mg}$, and placebo groups, respectively, reported adverse events. The reported adverse events that occurred more frequently in the combined golimumab group compared to placebo were nasopharyngitis, upper respiratory tract infection, fatigue, diarrhea, injection site reaction, and increase in alkaline aminotransferase or aspartate aminotransferase. ${ }^{15}$ The proportion of serious adverse events through Week 24 was 3.6\%, 6.4\%, and $6.5 \%$ in the golimumab $50 \mathrm{mg}$, golimumab $100 \mathrm{mg}$, and placebo groups, respectively. No death and no opportunistic infection, including tuberculosis, were observed during this study. In the long-term extension of the GO-RAISE study, there was no new safety signal. ${ }^{18}$ Through Week 268, serious adverse events were reported in $20.4 \%$ of patients treated with golimumab, including osteoarthritis, infection (pneumonia), worsening of AS, and depression. Serious infections were reported in $5.9 \%$ of patients. One patient died from pancreatic cancer and two others developed nonmelanoma skin cancer. Taken together, the safety profile of golimumab through 5 years of follow-up was consistent with that previously reported with this agent. In particular, there was no increase in malignancy, serious infection, or injection site reaction. The safety of golimumab in the GO-AHEAD study was similar to that reported in patients with AS, and no new safety signals were identified during treatment in patients with non-Rx AxSpA. ${ }^{16}$ An analysis of pooled data from the long-term extension clinical trials (up to 3 years) in patients with RA, AS, and PsA was recently performed. ${ }^{33}$ This analysis included 639 patients who received placebo and 2,226 patients who were treated with golimumab at a dose of $50 \mathrm{mg}(\mathrm{N}=1,249)$ or $100 \mathrm{mg}(\mathrm{N}=1,501)$ for 3 years. Overall, the results showed a safety profile similar to the known safety pattern of other anti-TNF $\alpha$ agents. There was a higher incidence of infection, lymphoma, and demyelinating events in patients treated by golimumab $100 \mathrm{mg}$ compared to the $50 \mathrm{mg}$ dosage. The higher incidence of these events appeared to be more common in patients with RA.

\section{Immunogenicity of golimumab in patients with Ax SpA}

The development of antibodies against anti-TNF $\alpha$ agents is an important issue, and such immunogenicity has been related to the development of progressive drug resistance and/or hypersensitivity reaction. ${ }^{34}$ Antibodies directed against golimumab were detected in a small number of patients: $4.1 \%$ of patients initially assigned to receive golimumab in the GO-RAISE study and $6.4 \%$ in the 5-year follow-up study. ${ }^{15,18}$ In the non-Rx Ax SpA population, such antibodies were detected in $4.1 \%$ of patients who had received golimumab. ${ }^{16}$ It is unclear whether antibodies to golimumab had an effect on treatment response in patients with AS, whereas in the non-Rx Ax SpA population, anti-golimumab antibodies did not influence ASAS20 response. ${ }^{15,16} \mathrm{~A}$ recent study performed in Taiwan analyzed the influence of antibodies to golimumab on the therapeutic response in clinical practice. Seventy-six patients, comprising 33 with RA and 43 with AS, were treated with golimumab $50 \mathrm{mg}$ once a month and followed up for 6 months. Serum trough levels of golimumab and anti-golimumab antibodies were assessed at this time point. The results showed that the proportion of 
anti-golimumab antibody positivity was higher in patients with RA (15.2\%) than in AS (2.3\%). For the AS group, serum golimumab trough serum levels were associated with therapeutic response (BASDAI 50) and ASDAS status. ${ }^{35}$

\section{The effects of golimumab on atherosclerosis}

It is well known that patients with chronic inflammatory rheumatic diseases, including AS and SpA, generally have an increased risk for the development of cardiovascular disease. ${ }^{36}$ Anti-TNF $\alpha$ agents seem to have a positive effect on this risk by reducing the incidence of cardiovascular events. ${ }^{37}$ The effects of golimumab on subclinical atherosclerosis were examined in a 12-month randomized placebo-controlled study. ${ }^{38}$ Intima-media thickness, pulse wave velocity, and augmentation index were evaluated at baseline, 6 and 12 months in 20 patients receiving golimumab $50 \mathrm{mg}$ and in 21 patients receiving placebo. There was no significant difference in the changes in vascular parameters at 6 and 12 months between the two groups, although a greater proportion of patients in the placebo group showed progression of both intima-media thickness and pulse wave velocity.

\section{Golimumab versus another disease- modifying drug in patients with $\mathrm{Ax}$ SpA}

No study to date has compared the efficacy of two different anti-TNF $\alpha$ agents in patients with AS or SpA. Recently, the effects of golimumab and pamidronate, an aminobisphosphonate, on clinical efficacy and MRI in patients with Ax SpA were reported in a randomized open-label trial. ${ }^{39}$ Indeed, aminobisphosphonates have anti-inflammatory effects that have been used for the treatment of AS. ${ }^{40}$ Twenty patients were assigned to receive golimumab $50 \mathrm{mg}$ and ten patients were assigned to pamidronate $60 \mathrm{mg}$ intravenously every 4 weeks. At Week 48, the proportion of patients who met ASAS20 response (primary outcome) was not significantly different between the two groups (golimumab 65\% and pamidronate $56 \%, P=0.69)$. ASDAS score, BASFI, CRP levels, and erythrocyte sedimentation rate were significantly improved in golimumab-treated patients, but not in the pamidronate group. Finally, MRI inflammation as evaluated by the Spondyloarthritis Research Consortium of Canada score decreased at the spine and/or SIJ in the golimumab group only. These results showed a similar clinical efficacy of pamidronate compared to golimumab, but these effects were not observed for all the assessed criteria or end points. ${ }^{39}$ The open-label design of the study limits the interpretation of the results.

\section{Comments: place of golimumab in the market}

In 2009, golimumab was approved by the US Food and Drug Administration and the European Medicines Agency for three indications, including AS, RA, and PsA. The recommended dosage is $50 \mathrm{mg}$ once monthly. For patients with a body weight greater than $100 \mathrm{~kg}$ who do not respond to the $50 \mathrm{mg}$ dosage after three or four injections, the treatment dose may be increased up to $100 \mathrm{mg}$. Golimumab may be used as monotherapy in AS and PsA, but concomitant use with methotrexate is recommended in patients with RA. Since 2015, golimumab is approved (in Europe but not in the USA) for the treatment of patients with non-Rx Ax SpA, in patients who do not respond to NSAIDs, and in those who have OSI (elevated CRP or positive MRI with bone marrow edema). In this regard, patients with inflammatory back pain who satisfy the clinical requirement of the ASAS classification criteria for Ax SpA (ie, patients with positive HLA-B27 antigen and two clinical criteria from the ASAS, but without OSI) are not eligible for treatment with golimumab. In addition, the $100 \mathrm{mg}$ dosage has not been specifically evaluated in the non-Rx Ax SpA population, and data regarding the efficacy and safety of this dosage are lacking. In the same way, there persists a need for data on the effects of golimumab (50 or $100 \mathrm{mg}$ ) on imaging features (inflammation as depicted by MRI) in these patients.

\section{Conclusion}

Golimumab has been shown to be effective in patients with radiographic and non- $\mathrm{Rx} \mathrm{Ax} \mathrm{SpA}$. This product is as safe and effective as other anti-TNF $\alpha$ agents. Although the $50 \mathrm{mg}$ dosage once monthly is the recommended dose, there is evidence that increasing the dose to $100 \mathrm{mg}$ may benefit patients who do not respond sufficiently to the low dose, especially those with a greater body weight. However, a higher dosage treatment is associated with an increased risk of infection, lymphoma, and demyelinating events. The longterm follow-up of patients with AS receiving golimumab demonstrated that the treatment response is sustained. Imaging studies performed in patients with AS showed that golimumab is able to efficiently reduce MRI inflammation at both the SIJ and the spine. Whether golimumab is capable of slowing the progression of ligamentous ossification remains debated, but data from the GO-RAISE study suggest that golimumab is associated with no acceleration of new bone formation. Patients with high levels of acute-phase reactants and positive spine/SIJ MRI will respond better to treatment than those without OSI. These predictive factors for response 
may be used in clinical practice to personalize the therapeutic approach. Golimumab is thus a valid therapeutic option to treat patients with AS and non-Rx Ax SpA in Europe.

\section{Disclosure}

The authors report no conflicts of interest in this work.

\section{References}

1. Dougados M, Baeten D. Spondyloarthritis. Lancet. 2011;377(9783): 2127-2137.

2. Braun J, Sieper J. Classification, diagnosis, and referral of patients with axial spondyloarthritis. Rheum Dis Clin North Am. 2012;38(3): 477-485.

3. Van der Linden S, Valkenburg HA, Cats A. Evaluation of diagnostic criteria for ankylosing spondylitis. A proposal for modification of the New York criteria. Arthritis Rheum. 1984;27(4):361-368.

4. Rudwaleit M, van der Heijde D, Landewé R, et al. The development of Assessment of SpondyloArthritis international Society classification criteria for axial spondyloarthritis (part II): validation and final selection. Ann Rheum Dis. 2009;68(6):777-783.

5. Kiltz U, Baraliakos X, Karakostas P, et al. Do patients with nonradiographic axial spondylarthritis differ from patients with ankylosing spondylitis? Arthritis Care Res (Hoboken). 2012;64(9):1415-1422.

6. Braun J, Sieper J. Ankylosing spondylitis. Lancet. 2007;369(9570): 1379-1390.

7. Boonen A, Chorus A, Miedema H, van der Heijde D, van der Tempel H, van der Linden S. Employment, work disability, and work days lost in patients with ankylosing spondylitis: a cross sectional study of Dutch patients. Ann Rheum Dis. 2001;60(4):353-358.

8. Zochling J, Van Der Heijde D, Burgos-Vargas R, et al. ASAS/EULAR recommendations for the management of ankylosing spondylitis. Ann Rheum Dis. 2006;65(4):442-452.

9. Braun J, Van Den Berg R, Baraliakos X, et al. 2010 update of the ASAS/EULAR recommendations for the management of ankylosing spondylitis. Ann Rheum Dis. 2011;70(6):896-904.

10. Toussirot É. Biologics in spondyloarthritis: TNF $\alpha$ inhibitors and other agents. Immunotherapy. 2015;7(6):669-681.

11. Mazumdar S, Greenwald D. Golimumab. MAbs. 2009;1(5):422-431.

12. Gelfer G, Perry L, Deodhar A. Golimumab for the treatment of axial spondyloarthritis. Expert Rev Clin Immunol. 2016;12(1):9-18.

13. Simponi : EPAR - European Medicines Agency. Summary of Product Characteristics. Available from: http://www.ema.europa.eu/docs/ en_GB/document_library/EPAR_-_Product_Information/human/000992/ WC500052368.pdf. Accessed April 1, 2016.

14. Rios Rodriguez V, Poddubnyy D. Golimumab for treatment of axial spondyloarthritis. Immunotherapy. 2016;8(2):107-115.

15. Inman RD, Davis JC Jr, Heijde D, et al. Efficacy and safety of golimumab in patients with ankylosing spondylitis: results of a randomized, double-blind, placebo-controlled, phase III trial. Arthritis Rheum. 2008;58(11):3402-3412.

16. Sieper J, van der Heijde D, Dougados M, et al. A randomized, doubleblind, placebo-controlled, sixteen-week study of subcutaneous golimumab in patients with active nonradiographic axial spondyloarthritis. Arthritis Rheumatol. 2015;67(10):2702-2712.

17. Braun J, Deodhar A, Inman RD, et al. Golimumab administered subcutaneously every 4 weeks in ankylosing spondylitis: 104-week results of the GO-RAISE study. Ann Rheum Dis. 2012;71(5):661-667.

18. Deodhar A, Braun J, Inman RD, et al. Golimumab administered subcutaneously every 4 weeks in ankylosing spondylitis: 5-year results of the GO-RAISE study. Ann Rheum Dis. 2015;74(4):757-761.

19. Creemers MC, Franssen MJ, van't Hof MA, Gribnau FW, van de Putte LB, van Riel PL. Assessment of outcome in ankylosing spondylitis: an extended radiographic scoring system. Ann Rheum Dis. 2005;64(1): $127-129$.
20. Maksymowych WP, Elewaut D, Schett G. Motion for debate: the development of ankylosis in ankylosing spondylitis is largely dependent on inflammation. Arthritis Rheum. 2012;64(6):1713-1719.

21. Van Der Heijde D, Landewe R, Baraliakos X, et al. Radiographic findings following two years of infliximab therapy in patients with ankylosing spondylitis. Arthritis Rheum. 2008;58(10):3063-3070.

22. Van Der Heijde D, Landewe R, Einstein S, et al. Radiographic progression of ankylosing spondylitis after up to two years of treatment with etanercept. Arthritis Rheum. 2008;58(5):1324-1331.

23. Van Der Heijde D, Salonen D, Weissman BN, et al. Assessment of radiographic progression in the spines of patients with ankylosing spondylitis treated with adalimumab for up to 2 years. Arthritis Res Ther. 2009;11(4):R127.

24. Haroon N, Inman RD, Learch TJ, et al. The impact of tumor necrosis factor $\alpha$ inhibitors on radiographic progression in ankylosing spondylitis. Arthritis Rheum. 2013;65(10):2645-2654.

25. Braun J, Baraliakos X, Hermann KG, et al. The effect of two golimumab doses on radiographic progression in ankylosing spondylitis: results through 4 years of the GO-RAISE trial. Ann Rheum Dis. 2014; 73(6):1107-1113.

26. Zochling J, Baraliakos X, Hermann KG, et al. Magnetic resonance imaging in ankylosing spondylitis. Curr Opin Rheumatol. 2007;19(4): 346-352.

27. Braun J, Baraliakos X, Hermann KG, et al. Golimumab reduces spinal inflammation in ankylosing spondylitis: MRI results of the randomised, placebo-controlled GO-RAISE study. Ann Rheum Dis. 2012; 71(6):878-884.

28. Braun J, Baraliakos X, Golder W, et al. Magnetic resonance imaging examinations of the spine in patients with ankylosing spondylitis, before and after successful therapy with infliximab: evaluation of a new scoring system. Arthritis Rheum. 2003;48(4):1126-1136.

29. Kirkham BW, Wasko MC, Hsia EC, et al. Effects of golimumab, an anti-tumour necrosis factor-alpha human monoclonal antibody, on lipids and markers of inflammation. Ann Rheum Dis. 2014;73(1): 161-169.

30. Wagner C, Visvanathan S, Braun J, et al. Serum markers associated with clinical improvement in patients with ankylosing spondylitis treated with golimumab. Ann Rheum Dis. 2012;71(5):674-680.

31. van der Heijde D, Deodhar A, Braun J, et al. The effect of golimumab therapy on disease activity and health-related quality of life in patients with ankylosing spondylitis: 2-year results of the GO-RAISE trial. GO-RAISE investigators. J Rheumatol. 2014;41(6):1095-1103.

32. van der Heijde D, Braun J, Deodhar A, et al. Comparison of three enthesitis indices in a multicentre, randomized, placebo-controlled trial of golimumab in ankylosing spondylitis (GO-RAISE). Rheumatology (Oxford). 2013;52(2):321-325.

33. Kay J, Fleischmann R, Keystone E, et al. Golimumab 3-year safety update: an analysis of pooled data from the long-term extensions of randomised, double-blind, placebo-controlled trials conducted in patients with rheumatoid arthritis, psoriatic arthritis or ankylosing spondylitis. Ann Rheum Dis. 2015;74(3):538-546.

34. Schaeverbeke T, Truchetet ME, Kostine M, Barnetche T, Bannwarth B, Richez C. Immunogenicity of biologic agents in rheumatoid arthritis patients: lessons for clinical practice. Rheumatology (Oxford). 2016; 55(2):210-220.

35. Chen DY, Chen YM, Hung WT, et al. Immunogenicity, drug trough levels and therapeutic response in patients with rheumatoid arthritis or ankylosing spondylitis after 24-week golimumab treatment. Ann Rheum Dis. 2015;74(12):2261-2264.

36. Peters MJ, Dijkmans BA, Nurmohamed MT, et al. Cardiovascular risk profile of patients with spondyloarthropathies, particularly ankylosing spondylitis and psoriatic arthritis. Semin Arthritis Rheum. 2004;34(3):585-592.

37. Toussirot É. Effects of TNF $\alpha$ inhibitors on adiposity and other cardiovascular risk factors: implications for the cardiovascular prognosis in patients with rheumatoid arthritis. Expert Opin Drug Saf. 2015;14(4):525-532. 
38. Tam LS, Shang Q, Kun EW, et al. The effects of golimumab on subclinical atherosclerosis and arterial stiffness in ankylosing spondylitis. a randomized, placebo-controlled pilot trial. Rheumatology (Oxford). 2014;53(6):1065-1074.

39. Mok CC, Li OC, Chan KL, Ho LY, Hui PK. Effect of golimumab and pamidronate on clinical efficacy and MRI inflammation in axial spondyloarthritis: a 48-week open randomized trial. Scand J Rheumatol. 2015; 44(6):480-486.
40. Toussirot E, Wendling D. Antiinflammatory treatment with bisphosphonates in ankylosing spondylitis. Curr Opin Rheumatol. 2007; 19(4):340-345.

\section{Publish your work in this journal}

Drug Design, Development and Therapy is an international, peerreviewed open-access journal that spans the spectrum of drug design and development through to clinical applications. Clinical outcomes, patient safety, and programs for the development and effective, safe, and sustained use of medicines are a feature of the journal, which has also been accepted for indexing on PubMed Central. The manuscript management system is completely online and includes a very quick and fair peer-review system, which is all easy to use. Visit http://www.dovepress.com/testimonials.php to read real quotes from published authors.

Submit your manuscript here: http://www.dovepress.com/drug-design-development-and-therapy-journal 